\title{
HLA-DM focuses on conformational flexibility around P1 pocket to catalyze peptide exchange
}

\section{Liusong Yin ${ }^{1}$ and Lawrence J. Stern ${ }^{1,2 *}$}

${ }^{1}$ Department of Pathology, University of Massachusetts Medical School, Worcester, MA, USA

${ }^{2}$ Department of Biochemistry and Molecular Pharmacology, University of Massachusetts Medical School, Worcester, MA, USA

\section{Edited by:}

Laura Santambrogio, Albert Einstein

College of Medicine, USA

\section{Reviewed by:}

Andrea Sant, David H. Smith Center for Vaccine Biology and Immunology, USA

Lisa K. Denzin, University of Medicine and Dentistry of NJ, USA

\section{*Correspondence:}

Lawrence J. Stern, Department of Pathology, Department of

Biochemistry and Molecular Pharmacology, University of Massachusetts Medical School, 368 Plantation Street, Worcester, MA 01605, USA

e-mail: lawrence.stern@

umassmed.edu
Peptides presented by major histocompatibility complex class II (MHCII) molecules to $\mathrm{CD} 4+\mathrm{T}$ cells play a central role in the initiation of adaptive immunity. This antigen presentation process is characterized by the proteolytic cleavage of foreign and self proteins, and loading of the resultant peptides onto $\mathrm{MHCll}$ molecules. Loading and exchange of antigenic peptides is catalyzed by a non-classical MHCII molecule, HLA-DM. The impact of HLA-DM on epitope selection has been appreciated for a long time. However, the molecular mechanism by which HLA-DM mediates peptide exchange remains elusive. Here, we review recent efforts in elucidating how HLA-DM works, highlighted by two recently solved costructures of HLA-DM bound to HLA-DO (a natural inhibitor of HLA-DM), or to HLA-DR1 (a common $\mathrm{MHCII}$ ). In light of these efforts, a model for HLA-DM action in which HLA-DM utilizes conformational flexibility around the $\mathrm{P} 1$ pocket of the $\mathrm{MHCll}$-peptide complex to catalyze peptide exchange is proposed.

Keywords: antigen presentation, epitope selection, MHCll-peptide complex, HLA-DM susceptibility, hydrogen bonds, conformational heterogeneity

\section{INTRODUCTION}

Major histocompatibility complex class II (MHCII) proteins are expressed constitutively on the surface of professional antigenpresenting cells, and induced by inflammatory stimuli on many other cell types. They display peptides derived from self or foreign antigens for recognition by $\mathrm{CD} 4+\mathrm{T}$ cells to initiate and regulate many aspects of adaptive immunity. Newly synthesized MHCII molecules associate with the invariant chain chaperone, which directs nascent MHCII to endosomal compartments before degradation by endosomal-resident cathepsin proteases, leaving small peptide fragments known as CLIP (class II-associated invariant chain peptide) bound in the MHCII-peptide binding groove (1-7). The release of CLIP and subsequent loading of antigenic peptides onto MHCII is catalyzed by a non-classical MHCII molecule, HLA-DM (8). HLA-DM also serves as a peptide editor by mediating the exchange of bound antigenic peptides, selecting for presentation of peptides with higher kinetic stability (9).

HLA-DM-mediated peptide exchange has been shown to play a key role in epitope selection. It has been found that HLA-DM extinguishes the presentation of cryptic epitopes and stimulates the presentation of immunodominant epitopes (10), and that the effects of HLA-DM editing can be altered by manipulation of the kinetic stability of MHCII-peptide complexes (11). We and others have demonstrated that the kinetic stability of MHCII-peptide complexes in the presence of HLA-DM directly correlates with immunogenicity (12-14). However, some immunodominant epitopes are found to have low affinities and low kinetic stabilities; notably most derive from self-antigens and are often associated in autoimmune diseases (15-18). In these cases, it is possible that self-peptides bound to MHCII alleles escaped HLA-DM editing due to downregulation, inhibition, or deficiency of HLA-DM in antigen presenting cells. This idea is supported by the observation that expression of HLA-DM decreased significantly in rheumatoid arthritis patients (19).

Due to the key role of HLA-DM in selection of both foreign pathogenic epitopes and autoimmune self-reactive epitopes, the mechanism of HLA-DM-mediated peptide exchange has been studied intensively. Here, we review the literature on efforts to determine how HLA-DM mediates peptide exchange and focus on two recent co-structures of HLA-DM in complex with MHCII binding partners.

\section{INVOLVEMENT AND CONTRIBUTION OF HYDROGEN BONDS TO HLA-DM SUSCEPTIBILITY}

The hydrogen bond network between peptide backbone and MHCII main chain ( $\alpha 51-\alpha 53)$ or conserved MHCII side-chain $(\alpha 62, \alpha 69, \beta 61, \beta 81$, and $\beta 82)$ residues, together with peptide sidechain binding $\mathrm{P} 1, \mathrm{P} 4, \mathrm{P} 6$, and $\mathrm{P} 9$ pockets are a characteristic feature of MHCII-peptide interaction $(20,21)$. The ability of HLA-DM to catalyze the exchange of a wide variety of peptides implicated the hydrogen bond network as an ideal target for HLA-DM (22). This idea was experimentally demonstrated in several studies, which in general highlighted a role for MHCII-peptide hydrogen bonds near P1 pocket (23-25). A seeming discrepancy came from two subsequent studies demonstrating that HLA-DM functions normally on MHCII-peptide complexes lacking conserved side-chain hydrogen bonds $(26,27)$, but it is important to note that neither study looked at the contribution of MHC main chain hydrogen bonds as described in Stratikos et al. Nevertheless, these studies suggested that individual hydrogen bonds may not be the key target 
for HLA-DM. A study of a MHCII mutant protein highly susceptible to HLA-DM action revealed weakened MHC-peptide hydrogen bonding, as shown by a novel hydrogen-deuterium exchange mass spectrometry assay, and structural alterations (discussed below), suggesting a connection between conformational features of MHCII-peptide complex, the MHCII-peptide hydrogen bond network, and HLA-DM susceptibility (28).

\section{CONFORMATIONAL HETEROGENEITY OF MHCII-PEPTIDE COMPLEXES IN HLA-DM SUSCEPTIBILITY}

Peptide-free MHCII molecules and certain MHCII variants loaded with peptides can adopt conformations distinct from the canonical structure observed by X-ray crystallography as judged by hydrodynamic, spectroscopic, and electrophoretic criteria (29-34). A role for these conformational changes in determining HLA-DM susceptibility has been appreciated more recently $(28,35-39)$. A recent crystal structure of a MHCII variant with increased HLA-DM affinity revealed conformational lability in the alpha $3_{10}$ helical and extended region near the N-terminal end of the bound peptide (28). Similar but smaller changes can be observed in crystal structures of certain MHCII-peptide complexes (34). A model for HLA-DM-mediated peptide exchange was presented, in which transient or low-abundant MHCII-peptide conformers are targeted by HLA-DM.

\section{INSIGHT FROM RECENT HLA-DM-HLA-DO AND HLA-DM-HLA-DR1 STRUCTURES}

Recently, two X-ray crystal co-structures of HLA-DM bound to MHCII protein targets have helped to illuminate the mechanism of HLA-DM-mediated peptide exchange. In one, HLA-DM was bound to HLA-DO, a natural inhibitor of HLA-DM (40). In the other, HLA-DM was bound to HLA-DR1, a common MHCII allele, for which a truncated peptide was covalently trapped in the C-terminal side of the peptide binding site (41). In both cases HLA-DM binds to the MHCII protein in a side-by-side arrangement, with HLA-DM riding slightly above of the N-terminal side of the MHCII-peptide binding groove (Figure 1).

HLA-DO is a non-classical MHCII protein that forms a stable complex with HLA-DM and inhibits HLA-DM function, in vitro (42-44), and in vivo (45). In the HLA-DM-HLA-DO structure, HLA-DO adopts an overall topology highly similar to that of classical MHCII molecules such as HLA-DR1, with substantial alpha subunit alternations (40). The key differences are located in the $3_{10}$ helix and extended strand region of the alpha subunit, with HLA-DO residues $\alpha \mathrm{W} 43$ and $\alpha \mathrm{F} 51$ flipped out from their usual partially buried conformations to interact directly with HLA-DM. In addition, $\alpha$ F54 has moved into the $\mathrm{P} 1$ pocket, possibly giving insight into how empty MHCII is stabilized after peptide release (32). Given the fact that HLA-DM does not form stable complex with classical MHCII molecules, and the high structural similarity between HLA-DO and classical MHCII molecules, the HLA-DM-HLA-DO interactions may represent an intermediate stage during HLA-DM catalyzed peptide exchange from MHCII. This idea was supported by the almost identical match of HLA-DM and MHCII residues implicated by mutagenesis in the catalytic mechanism $(33,46,47)$, and HLADM and HLA-DO residues found in the interface in the crystal structure (40).

\section{A} HLA-DM-HLA-DO

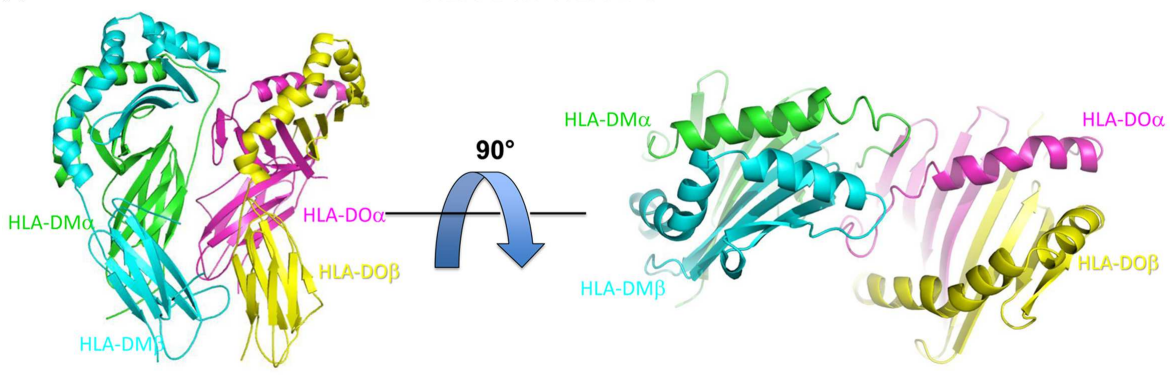

B

HLA-DM-HLA-DR1
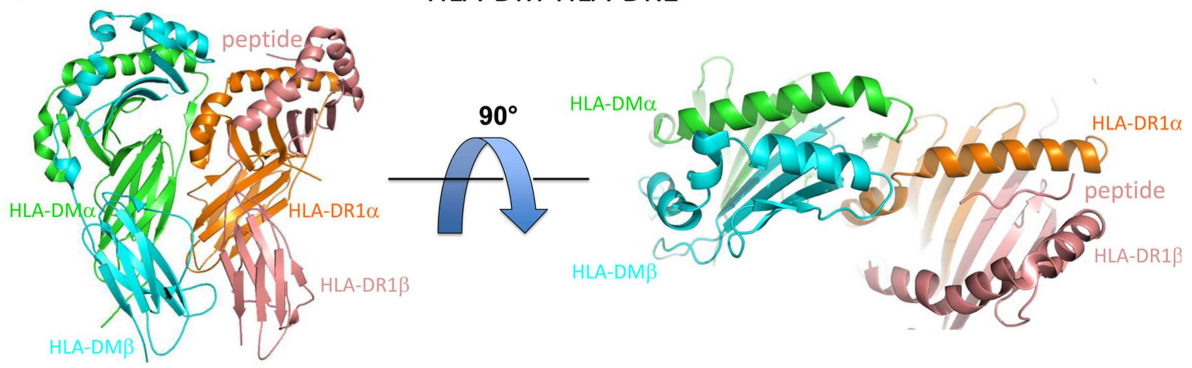

FIGURE 1 | Overview of HLA-DM-HLA-DO and HLA-DM-HLA-DR1 structures. (A) Side view (left) and top view (right) of HLA-DM-HLA-DO structure (PDB ID: 4IOP). HLA-DM $\alpha$ is colored green, HLA-DM $\beta$ blue, HLA-DO $\alpha$ pink, and HLA-DO $\beta$ yellow. (B) Side view (left) and top view (right) of HLA-DM-HLA-DR1 structure (PDB ID: 4FOX). HLA-DM is colored the same, HLA-DR1 $\alpha$ orange, and HLA-DR1 $\beta$ magenta. The peptide (colored magenta) is located in the $\mathrm{C}$-terminal end of the peptide binding groove. 
The structure of HLA-DM bound to HLA-DR1 carrying a covalently linked truncated peptide (41) also provides a model of an intermediate in HLA-DM-mediated peptide exchange. As in the HLA-DM-HLA-DO structure, $\alpha \mathrm{W} 43$ in HLA-DR1 rotates out of the lateral wall of $\mathrm{P} 1$ pocket to directly interact with HLADM by forming a hydrogen bond with HLA-DM $\alpha$ N125. The $\alpha \mathrm{W} 43$ flip is accompanied by a conformational change in MHCII alpha $3_{10}$ helix and extended strand region $(\alpha 46-\alpha 55)$ adjacent to the P1 pocket. Although HLA-DO also exhibits conformational changes in this region when bound to HLA-DM, the conformation adopted is different (Figure 2). In addition, HLA-DR1 $\alpha$ F51 in the HLA-DM-HLA-DR1 structure, rather than HLA-DO $\alpha$ F54 in the HLA-DM-HLA-DO structure, repositions into the P1 pocket to stabilize empty MHCII. It is possible that the three views of the MHCII extended strand region observed in the various crystal structures represent different conformers from an ensemble adopted by a highly dynamic region.

Pos et al. suggested a model for HLA-DM-mediated peptide exchange based on the HLA-DM-HLA-DR1 structure. In that model, the $\mathrm{N}$-terminus of a bound peptide dissociates from the P1 pocket, allowing HLA-DR1 $\alpha \mathrm{W} 43$ to flip out and interact with
HLA-DM. Meanwhile, HLA-DR1 $\alpha$ F51 rotates into P1 pocket to stabilize partially empty HLA-DR1. An exchange peptide with a hydrophobic N-terminus could compete with HLA-DR1 $\alpha$ F51 for the binding to P1 pocket, and displace HLA-DM and the original peptide, reversing the conformational changes.

\section{OUTSTANDING QUESTIONS IN HLA-DM-MEDIATED PEPTIDE EXCHANGE}

It is important to understand the process of HLA-DM-mediated peptide exchange, which is crucial for determining HLA-DM binding and susceptibility, and how peptide sequence relates to those properties. Proposed models agree on some aspects but differ in important ways on others. General agreement has been reached on the general structure of an intermediate in the peptide exchange reaction, in which HLA-DM is bound to MHCII in an altered conformation, involving a reorganized $33_{10}$ helix and extended strand region of the MHC II alpha subunit with disruption of MHCII-peptide hydrogen bonds, blockage of the P1 pocket, and inhibition of peptide binding. However, the disposition of aromatic residues in the $\mathrm{P} 1$ region, particularly $\alpha \mathrm{F} 51$ and $\alpha \mathrm{F} 54$, is not clear, and whether or not changes occur in the C-terminal side of

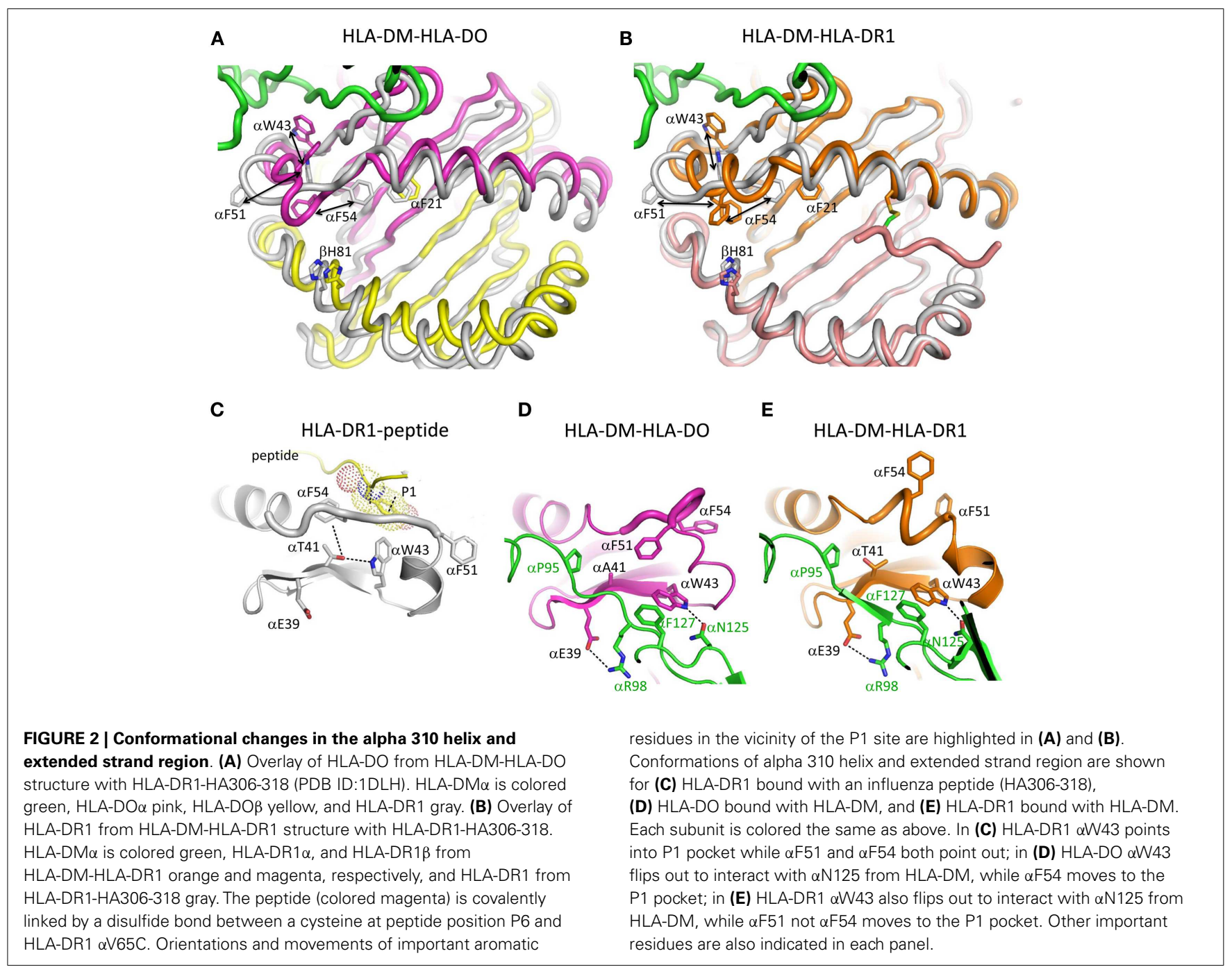


peptide binding groove remains elusive. Also whether peptide is bound in the intermediate complex has not been tested directly and currently is not known.

The mechanism by which a HLA-DM-bound intermediate resolves to yield an exchanged MHCII-peptide complex also is not clear. One outstanding question is in whether the exchanging peptide binds dominantly via $\mathrm{P} 1$ pocket competition, or through interactions throughout the entire peptide binding groove. It is important to understand how peptide sequence determines the ability to be exchanged onto MHCII during antigen presentation, as this appears to be the crucial factor for epitope selection. A model involving a tetramolecular HLA-DM-MHCII-two peptide intermediate was proposed based on kinetics and spin-label studies (48). This model was suggested to explain observations of accelerated release of pre-bound peptide in the presence of free exchange peptide (49-51).

\section{REFERENCES}

1. Bakke O, Dobberstein B. MHC class II-associated invariant chain contains a sorting signal for endosomal compartments. Cell (1990) 63:707-16. doi:10.1016/00928674(90)90137-4

2. Roche PA, Cresswell P. Invariant chain association with HLA-DR molecules inhibits immunogenic peptide binding. Nature (1990) 345:615-8. doi:10.1038/345615a0

3. Avva RR, Cresswell P. In vivo and in vitro formation and dissociation of HLA-DR complexes with invariant chain-derived peptides. Immunity (1994) 1:763-74. doi:10.1016/ S1074-7613(94)80018-9

4. Germain RN. MHC-dependent antigen processing and peptide presentation: providing ligands for $\mathrm{T}$ lymphocyte activation. Cell (1994) 76:287-99. doi:10.1016/ 0092-8674(94)90336-0

5. Ghosh P, Amaya M, Mellins E, Wiley DC. The structure of an intermediate in class II MHC maturation: CLIP bound to HLA-DR3. Nature (1995) 378:457-62. doi:10. 1038/378457a0

6. Jasanoff A, Park SJ, Wiley DC. Direct observation of disordered regions in the major histocompatibility complex class II-associated invariant chain. Proc Natl Acad Sci U $S$ A (1995) 92:9900-4. doi:10.1073/ pnas.92.21.9900

7. Hsieh CS, Deroos P, Honey K, Beers C, Rudensky AY. A role for cathepsin $\mathrm{L}$ and cathepsin $\mathrm{S}$ in peptide generation for MHC class II presentation. J Immunol (2002) 168:2618-25.

8. Sloan VS, Cameron P, Porter G, Gammon M, Amaya M, Mellins E, et al. Mediation by HLA-DM of dissociation of peptides from HLA-DR.
Nature (1995) 375:802-6. doi:10. 1038/375802a0

9. Kropshofer H, Vogt AB, Moldenhauer G, Hammer J, Blum JS, Hammerling GJ. Editing of the HLADR-peptide repertoire by HLA-DM.

10. Nanda NK, Sant AJ. DM determines the cryptic and immunodominant fate of T cell epitopes. J Exp Med (2000) 192:781-8. doi:10.1084/jem. 192.6.781

11. Lazarski CA, Chaves FA, Sant AJ. The impact of DM on MHC class II-restricted antigen presentation can be altered by manipulation of MHC-peptide kinetic stability. J Exp Med (2006) 203:1319-28. doi:10. 1084/jem.20060058

12. Hall FC, Rabinowitz JD, Busch R, Visconti KC, Belmares M, Patil NS, et al. Relationship between kinetic stability and immunogenicity of HLA-DR4/peptide complexes. Eur J Immunol (2002) 32:662-70. doi:10. 1002/1521-4141(200203)32:3<662: :AID-IMMU662>3.0.CO;2-5

13. Amria S, Hajiaghamohseni LM, Harbeson C, Zhao D, Goldstein O, Blum JS, et al. HLA-DM negatively regulates HLA-DR4-restricted collagen pathogenic peptide presentation and $\mathrm{T}$ cell recognition. Eur J Immunol (2008) 38:1961-70. doi: 10.1002/eji.200738100 Amorocho O, Stern LJ. HLA-DM constrains epitope selection in the human CD4 $\mathrm{T}$ cell response to vaccinia virus by favoring the presentation of peptides with longer HLADM-mediated half-lives. J Immunol (2012) 189:3983-94. doi:10.4049/ jimmunol.1200626

15. Muraro PA, Vergelli M, Kalbus M, Banks DE, Nagle JW, Tranquill EMBO J (1996) 15:6144-54.

14. Yin L, Calvo-Calle JM, Dominguez-

\section{CONCLUSION}

Previous efforts and particularly two recent co-structures have shed light on the mechanism of HLA-DM-mediated peptide exchange. HLA-DM appears to promote peptide exchange by disrupting the MHCII-peptide hydrogen bond network at the $\mathrm{N}$-terminal end of the peptide binding groove, and by disrupting MHCII-peptide interactions in the P1 pocket through stabilization of an altered conformation of the $3_{10}$ helix and extended strand region. Important questions still remain about how the sequence of MHCII-bound peptide determines MHCIIconformation, HLA-DM susceptibility, and peptide exchange function.

\section{ACKNOWLEDGMENTS}

This work was supported by NIH grants AI-38996 and AI-48833.

LR, et al. Immunodominance of a low-affinity major histocompatibility complex-binding myelin basic protein epitope (residues 111-129) in HLA-DR4 $\left(\mathrm{B1}^{\star} 0401\right)$ subjects is associated with a restricted $\mathrm{T}$ cell receptor repertoire. J Clin Invest (1997) 100:339-49. doi:10. 1172/JCI119539

16. Harrington CJ, Paez A, Hunkapiller T, Mannikko V, Brabb T, Ahearn $\mathrm{M}$, et al. Differential tolerance is induced in $\mathrm{T}$ cells recognizing distinct epitopes of myelin basic protein. Immunity (1998) 8:571-80. doi:10.1016/S10747613(00)80562-2

17. Patil NS, Pashine A, Belmares MP, Liu W, Kaneshiro B, Rabinowitz J, et al. Rheumatoid arthritis (RA)associated HLA-DR alleles form less stable complexes with class II-associated invariant chain peptide than non-RA-associated HLADR alleles. J Immunol (2001) 167:7157-68.

18. Bielekova B, Sung MH, Kadom N, Simon R, Mcfarland H, Martin R. Expansion and functional relevance of high-avidity myelinspecific CD4+ $\mathrm{T}$ cells in multiple sclerosis. J Immunol (2004) 172:3893-904.

19. Louis-Plence P, Kerlan-Candon S, Morel J, Combe B, Clot J, Pinet $\mathrm{V}$, et al. The down-regulation of HLA-DM gene expression in rheumatoid arthritis is not related to their promoter polymorphism. J Immunol (2000) 165:4861-9.

20. Stern LJ, Brown JH, Jardetzky TS, Gorga JC, Urban RG, Strominger JL, et al. Crystal structure of the human class II MHC protein HLA-DR1 complexed with an influenza virus peptide. Nature (1994) 368:215-21. doi: $10.1038 / 368215 \mathrm{a} 0$

21. McFarland BJ, Beeson C. Binding interactions between peptides and proteins of the class II major histocompatibility complex. Med Res Rev (2002) 22:168-203. doi:10. 1002/med.10006

22. Weber DA, Evavold BD, Jensen PE. Enhanced dissociation of HLA-DR-bound peptides in the presence of HLA-DM. Science (1996) 274:618-20. doi:10.1126/science.274.5287.618

23. Sant AJ, Beeson C, McFarland B, Cao J, Ceman S, Bryant PW, et al. Individual hydrogen bonds play a critical role in MHC class II: peptide interactions: implications for the dynamic aspects of class II trafficking and DM-mediated peptide exchange. Immunol Rev (1999) 172:239-53.

24. Stratikos E, Wiley DC, Stern LJ. Enhanced catalytic action of HLADM on the exchange of peptides lacking backbone hydrogen bonds between their $\mathrm{N}$-terminal region and the MHC class II alpha-chain. J Immunol (2004) 172:1109-17.

25. Narayan K, Chou CL, Kim A, Hartman IZ, Dalai S, Khoruzhenko S, et al. HLA-DM targets the hydrogen bond between the histidine at position $\beta 81$ and peptide to dissociate HLA-DR-peptide complexes. Nat Immunol (2007) 8:92-100. doi: 10.1038/nil414

26. Zhou Z, Callaway KA, Weber DA, Jensen PE. Cutting edge: HLADM functions through a mechanism that does not require specific conserved hydrogen bonds in class II MHC-peptide complexes. I Immunol (2009) 183:4187-91. doi: 10.4049/jimmunol.0901663 
27. Ferrante A, Gorski J. Cutting edge: HLA-DM-mediated peptide exchange functions normally on MHC class IIpeptide complexes that have been weakened by elimination of a conserved hydrogen bond. J Immunol (2010) 184:1153-8. doi:10.4049/jimmunol.0902878

28. Painter CA, Negroni MP, Kellersberger KA, Zavala-Ruiz Z, Evans JE, Stern LJ. Conformational lability in the class II MHC 310 helix and adjacent extended strand dictate HLA-DM susceptibility and peptide exchange. Proc Natl Acad Sci U S A (2011) 108:19329-34. doi:10.1073/ pnas.1108074108

29. Natarajan SK, Stern LJ, SadeghNasseri S. Sodium dodecyl sulfate stability of HLA-DR1 complexes correlates with burial of hydrophobic residues in pocket 1 . J Immunol (1999) 162:3463-70.

30. Zarutskie JA, Sato AK, Rushe MM, Chan IC, Lomakin A, Benedek GB, et al. A conformational change in the human major histocompatibility complex protein HLA-DR1 induced by peptide binding. Biochemistry (1999) 38:5878-87. doi: 10.1021/bi983048m

31. Sato AK, Zarutskie JA, Rushe MM, Lomakin A, Natarajan SK, SadeghNasseri $S$, et al. Determinants of the peptide-induced conformational change in the human class II major histocompatibility complex protein HLA-DR1. J Biol Chem (2000) 275:2165-73. doi:10.1074/ jbc.275.3.2165

32. Painter CA, Cruz A, Lopez GE, Stern LJ, Zavala-Ruiz Z. Model for the peptide-free conformation of class II MHC proteins. PLoS ONE (2008) 3:e2403. doi:10.1371/journal.pone. 0002403

33. Anders AK, Call MJ, Schulze MS, Fowler KD, Schubert DA, Seth NP, et al. HLA-DM captures partially empty HLA-DR molecules for catalyzed removal of peptide. Nat Immunol (2011) 12:54-61. doi:10. 1038/ni.1967

34. Painter CA, Stern LJ. Conformational variation in structures of classical and non-classical MHCII proteins and functional implications. Immunol Rev (2012) 250:144-57. doi:10.1111/imr.12003

35. Chou CL, Sadegh-Nasseri S. HLADM recognizes the flexible conformation of major histocompatibility complex class II. J Exp Med (2000) 192:1697-706. doi:10.1084/ jem.192.12.1697

36. Sadegh-Nasseri S, Natarajan $S$, Chou CL, Hartman IZ, Narayan K, Kim A. Conformational heterogeneity of MHC class II induced upon binding to different peptides is a key regulator in antigen presentation and epitope selection. Immunol Res (2010) 47:56-64. doi:10.1007/s12026-009-8138-1

37. Ferrante A. HLA-DM: Arbiter conformationis. Immunology (2012) 138:85-92. doi:10.1111/imm.12030

38. Ferrante A, Gorski J. A Peptide/MHCII conformer generated in the presence of exchange peptide is substrate for HLA-DM editing. Sci Rep (2012) 2:386. doi:10.1038/ srep00386

39. Sadegh-Nasseri S, Chou CL, Hartman IZ, Kim A, Narayan K. How HLA-DM works: recognition of MHC II conformational heterogeneity. Front Biosci (Schol Ed) (2012) 4:1325-32. doi:10.2741/ S334

40. Guce AI, Mortimer SE, Yoon T, Painter CA, Jiang W, Mellins ED, et al. HLA-DO acts as a substrate mimic to inhibit HLA-DM by a competitive mechanism. Nat Struct Mol Biol (2013) 20:90-8. doi:10. 1038/nsmb. 2460

41. Pos W, Sethi DK, Call MJ, Schulze MS, Anders AK, Pyrdol J, et al. Crystal structure of the HLA-DM-HLA-DR1 complex defines mechanisms for rapid peptide selection. Cell (2012) 151:1557-68. doi:10.1016/j.cell.2012.11.025

42. Denzin LK, Sant'Angelo DB, Hammond C, Surman MJ Cresswell P. Negative regulation by HLA-DO of MHC class II-restricted antigen processing. Science (1997) 278:106-9. doi:10.1126/science.278.5335.106

43. van Ham SM, Tjin EP, Lillemeier BF, Gruneberg U, Van Meijgaarden KE, Pastoors L, et al. HLA-DO is a negative modulator of HLA-DM-mediated MHC class II peptide loading. Curr Bio (1997) 7:950-7. doi:10.1016/S09609822(06)00414-3

44. Yoon T, Macmillan H, Mortimer SE Jiang W, Rinderknecht $\mathrm{CH}$, Stern LJ, et al. Mapping the HLA-DO/HLADM complex by FRET and mutagenesis. Proc Natl Acad Sci U S A (2012) 109:11276-81. doi:10.1073/ pnas.1113966109

45. Fallas JL, Tobin HM, Lou O, Guo D, Sant'Angelo DB, Denzin LK. Ectopic expression of HLA-DO in mouse dendritic cells diminishes MHC class II antigen presentation. J Immunol (2004) 173:1549-60.

46. Doebele RC, Busch R, Scott HM Pashine A, Mellins ED. Determination of the HLA-DM interaction site on HLA-DR molecules. Immunity (2000) 13:517-27. doi:10.1016/ S1074-7613(00)00051-0

47. Pashine A, Busch R, Belmares MP, Munning JN, Doebele RC, Buckingham $\mathrm{M}$, et al. Interaction of HLADR with an acidic face of HLADM disrupts sequence-dependent interactions with peptides. Immunity (2003) 19:183-92. doi:10.1016/ S1074-7613(03)00200-0

48. Ferrante A, Anderson MW, Klug CS, Gorski J. HLADM mediates epitope selection by a "compare-exchange" mechanism when a potential peptide pool is available. PLoS ONE (2008) 3:e3722. doi:10.1371/journal.pone.0003722

49. Pedrazzini T, Sette A, Albertson M, Grey HM. Free ligand-induced dissociation of MHC-antigen complexes. J Immunol (1991) 146:3496-501.

50. de Kroon AI, McConnell HM. Enhancement of peptide antigen presentation by a second peptide. Proc Natl Acad Sci U S A (1993) 90:8797-801. doi:10.1073/pnas.90. 19.8797

51. de Kroon AI, McConnell HM. Kinetics and specificity of peptideMHC class II complex displacement reactions. J Immunol (1994) 152:609-19.

Conflict of Interest Statement: The authors declare that the research was conducted in the absence of any commercial or financial relationships that could be construed as a potential conflict of interest.

Received: 12 August 2013; accepted: 03 October 2013; published online: 17 October 2013.

Citation: Yin L and Stern LJ (2013) HLADM focuses on conformational flexibility around $P 1$ pocket to catalyze peptide exchange. Front. Immunol. 4:336. doi 10.3389/fimmu.2013.00336

This article was submitted to Antigen Presenting Cell Biology, a section of the journal Frontiers in Immunology.

Copyright (C) 2013 Yin and Stern. This is an open-access article distributed under the terms of the Creative Commons Attribution License (CC BY). The use, distribution or reproduction in other forums is permitted, provided the original author(s) or licensor are credited and that the original publication in this journal is cited, in accordance with accepted academic practice. No use, distribution or reproduction is permitted which does not comply with these terms. 